\title{
Study on treatment of acid mine drainage by nano zero-valent iron synergistic with SRB immobilized particles
}

\author{
Xianjun Wang ${ }^{1}$, Junzhen $\mathrm{Di}^{{ }^{\dagger}}$, Bing Liang${ }^{2}$, Yu Yang ${ }^{1}$, Yanrong Dong ${ }^{1}$, Mingxin Wang ${ }^{1}$ \\ ${ }^{1}$ College of Civil Engineering, Liaoning Technical University, Fuxin 123000, China \\ ${ }^{2}$ College of Mechanics and Engineering, Liaoning Technical University, Fuxin 123000, China
}

\begin{abstract}
In view of the serious pollution and high cost of treatment of acid mine drainage (AMD) in coal mine, the polyving akohol (PVA) and boric acid embedding cross-linking method was used to prepare the immobilized particles for treatment of AMD with sulfate-reducing bacteria (SRB) and nano zero-valent iron (nano-Fe ${ }^{0}$ ) as the main body. In order to explore the specification and dosage of each matrix component of immobilized particle, a series of single factor tests and orthogonal tests were carried out to determine the optimal ratio of each matrix component. The results shows that when the SRB quality additive percentage was $30 \%$, the nano- $\mathrm{Fe}^{0}$ dosage was $4 \%$, the corn cob particle size was 60 mesh and the dosage was $3 \%$, the $\mathrm{SO}_{4}^{2-}, \mathrm{Cr}^{6+}$ and $\mathrm{Cr}^{3+}$ removal rates were $82.99 \%, 99.78 \%$ and $38.78 \%$, respectively, the TFe and COD release rates were $4.26 \mathrm{mg} \cdot \mathrm{L}^{-1}$ and $1,033.4 \mathrm{mg} \cdot \mathrm{L}^{-1}$, respectively, and the $\mathrm{pH}$ value was 8.04 , and the treatment effect was the best.
\end{abstract}

Keywords: Acid mine drainage, Corn cob, Immobilized particles, Nano-Fe ${ }^{0}$, Sulfate-reducing bacteria

\section{Introduction}

AMD is characterized by low $\mathrm{pH}$, high sulfate content, and a variety of highly toxic heavy metal ions [1]. Such water, if discharged directly into the natural water, will cause serious pollution to the environment and greatly endanger the safety of animals, plants and human life. Therefore, it is urgent to repair the AMD produced by coal mining.

In recent years, domestic and foreign scholars have carried out a lot of research on treatment and remediation. At present, the basic treatment methods include neutralization method [2], wetland method [3] and microbial method [4]. However, the neutralization method will produce a large amount of sediment rich in heavy metals, which not only needs to be cleaned regularly, but also can easily lead to secondary pollution due to improper disposal [5]. Although the wetland method is easy to maintain and manage, its application is also restricted because it covers a large area and has a low treatment load, so $\mathrm{H}_{2} \mathrm{~S}$ produced by microorganisms cannot be thoroughly treated, and the treatment effect fluctuates greatly with the season [6]. In recent years, microbial method has become a research hotspot in the world due to its advantages such as multiple types of heavy metals, thorough treatment, low treatment cost and environmental friendliness [7]. SRB is a prokaryotic microorganism living in an anaerobic environment. It can reduce $\mathrm{SO}_{4}{ }^{2-}$ and $S^{2-}$ by organic matter, as shown in Eq. (1)-(2) [8, 9]. The $S^{2-}$ produced by SRB metabolism is easy to form stable metal sulfide precipitation with heavy metal ions [10]. SRB has good regulation effect on sulphate, heavy metal and $\mathrm{pH}$ value in AMD. Therefore, SRB has become the representative microorganism in microbial method.

$$
\begin{gathered}
\mathrm{CH}_{3} \mathrm{COOH}+2 \mathrm{H}_{2} \mathrm{O} \rightarrow 2 \mathrm{CO}_{2}+8 \mathrm{H}^{+}+8 \mathrm{e}^{-} \\
\mathrm{SO}_{4}{ }^{2-}+8 \mathrm{H}^{+}+8 \mathrm{e}^{-} \rightarrow \mathrm{S}^{2-}+4 \mathrm{H}_{2} \mathrm{O}
\end{gathered}
$$

The growth and metabolism of SRB requires the use of carbon sources. However, traditional carbon sources cannot release organic matter slowly, and SRB metabolism and utilization of organic matter are limited, which can easily lead to excessive COD concentration in the water in the early stage of the experiment and insufficient
This is an Open Access article distributed under the terms of the Creative Commons Attribution Non-Commercial License (http://creativecommons.org/licenses/by-nc/3.0/) which permits unrestricted non-commercial use, distribution, and reproduction in any medium, provided the original work is properly cited.

Copyright (C) 2021 Korean Society of Environmental Engineers
Received June 12, 2020 Accepted October 13, 2020

${ }^{\dagger}$ Corresponding author

Email: dijunzhen@126.com

Tel: +86-13941889524

ORCID: 0000-0002-3608-9436 
organic matter in the later stage [11], which greatly affects the effect of treating AMD by biological method.

To a great extent, it affects the effect of treating $\mathrm{AMD}$ by biological method. In contrast, abandoned biomass materials commonly found in agriculture, such as corn cobs and peanut shells, can continuously and stably provide carbon sources for SRB through the slow release of carbon sources under the action of hydrolyzed microorganisms [12]. In order to make the carbon source be better used by SRB metabolism without causing secondary organic pollution of water, and considering the huge yield of corn crops in northern China, which is easy to obtain, and the high content of glucose and galactose in the corn crop [13], this experiment adopts the cohesive carbon source method and adopts the corn cob as the immobilized grain nutrient.

In addition to sufficient carbon sources, SRB also needs enough electron donors to meet metabolic activities during its growth [14]. Zero-valent iron is chemically active and has a low electrode potential $\left(\mathrm{E}^{0}\left(\mathrm{Fe}^{2+} / \mathrm{Fe}\right)=-0.440 \mathrm{~V} ; \mathrm{E}^{0}\left(\mathrm{Fe}^{3+} / \mathrm{Fe}^{2+}\right)=0.771 \mathrm{~V}\right)$, therefore, it has a high reduction capacity and can reduce ions, compounds and some organic compounds with strong oxidation properties [15]. The oxidation of $\mathrm{Fe}^{0}$ particles produces the low redox potential environment required by SRB, which achieves the optimal growth of SRB, and SRB can use the $\mathrm{H}_{2}$ produced by iron oxidation as an effective electron donor [16]. Nano- $\mathrm{Fe}^{0}$ is an ultrafine iron powder with particle diameter of order of magnitude between 1-100 nm. Compared with conventional zero-valent iron particles, nano- $\mathrm{Fe}^{0}$ has a larger specific surface area, which can provide more active sites for pollutants, thus improving treatment efficiency. At the same time, the enhanced surface activity can handle more types of pollutants, which is more conducive to the synchronous removal of multiple pollutant ions in $\mathrm{AMD}$ [17]. nano- $\mathrm{Fe}^{0}$ can effectively degrade various pollutants such as nitrate, heavy metal and dye, and is widely used to treat pollutants in aqueous solutions [18]. It is reported that the SRB-Fe ${ }^{0}$ system has a synergistic effect on the removal of heavy metals. $\mathrm{Fe}^{0}$ can effectively remove metals, and finally the SRB can form relatively stable metal sulfides [9]. In the SRB-Fe ${ }^{0}$ system, SRB and $\mathrm{Fe}^{0}$ are directly in contact with pollutants, and low acidity and high concentration of heavy metals are not conducive to the growth of SRB. Microbiological immobilization technology can effectively avoid this problem by embedding $\mathrm{SRB}$ and nano- $\mathrm{Fe}^{0}$ into particles, promoting the continuous growth of SRB and its adaptability to harsh environment.

Based on this, this paper proposes to prepare nano- $\mathrm{Fe}^{0} \mathrm{SRB}$ immobilized particles by using microbial immobilization technology, using nano- $\mathrm{Fe}^{0}$ and SRB as cohesive carbon source, and using corn cob as cohesive carbon source for the treatment of $\mathrm{AMD}$. Single factor test and orthogonal test were carried out to determine the optimal ratio of SRB dosage, nano-Fe ${ }^{0}$ dosage, corn cob dosage and corn cob particle size, so as to obtain a kind of immobilized grain with high treatment efficiency and strong adaptability. On this basis, EDS, XRD and SEM were used to analyze the composition, surface and internal structure of the particles before and after the reaction. Further research on the internal mechanism of immobilized particles to remove pollutants is expected to provide some theoretical reference for the practical application of nano- $\mathrm{Fe}^{0} \mathrm{SRB}$ immobilized particles.

\section{Material and Methods}

\subsection{Experimental Materials and Water Samples}

The corn cob used in the experiment was taken from the local farmland in Fuxin, Liaoning province. After washing, drying, crushing and sieving, the corn cob was made into 60 mesh, 100 mesh and 200 mesh particles respectively. The nano- $\mathrm{Fe}^{0}$ particles selected for the experiment were purchased from Beijing Deke Daojin Science And Technology Co., LTD., with a particle size of $100 \mathrm{~nm}$ and a purity of $99.99 \%$. Nano-Fe ${ }^{0}$ is sealed and stored in a dry and cool environment. It is not suitable to be exposed to the air for a long time to prevent agglomeration caused by moisture.

The SRB were cultured in the laboratory. The surface moist soil at the foot of gangue hill, Xinqiu District, Fuxin city, Liaoning Province was used as SRB seeding mud. Wipe the inside of the zipper bag with $75 \%$ ethanol, get the zipper bag after sterilization, and put the soil into the zipper bag to seal. The soil samples retrieved from the outdoor were immediately added to sterile deionized water at a solid-liquid ratio of $20 \mathrm{~g} / 100 \mathrm{~mL}$. Under aseptic conditions, $100 \mathrm{~mL}$ of the above liquid was added to the $400 \mathrm{~mL}$ modified Starkey medium, and the SRB was obtained by enrichment semi-continuous culture in an $(37 \pm 1)^{\circ} \mathrm{C}$ constant temperature $\mathrm{CO}_{2}$ anaerobic incubator. The above SRB was inoculated into the new medium at $10 \%$ of the inoculation amount every 5 days, and inoculated for 4 times continuously, until the culture medium produced a large amount of black precipitation, and the smell of rotten eggs when the bottle mouth was opened, indicating that a large amount of SRB had been enriched in the medium. The concentration of the cultured SRB was $1 \times 10^{6} \mathrm{~mL}^{-1}$.

The test water sample is a simulated water sample configured according to the water quality characteristics of the local mining area. Among them, the water quality test results of the local mining area were $\mathrm{pH}=4.0 \pm 0.2$, and the mass concentrations of $\mathrm{SO}_{4}{ }^{2-}$, $\mathrm{Cr}^{6+}, \mathrm{Cr}^{3+}, \mathrm{Mn}^{2+}, \mathrm{Cu}^{2+}$ and $\mathrm{Zn}^{2+}$ were $816 \mathrm{mg} \cdot \mathrm{L}^{-1}, 9.9 \mathrm{mg} \cdot \mathrm{L}^{-1}, 20.1$ $\mathrm{mg} \cdot \mathrm{L}^{-1}, 1.6 \mathrm{mg} \cdot \mathrm{L}^{-1}, 0.8 \mathrm{mg} \cdot \mathrm{L}^{-1}$ and $1.2 \mathrm{mg} \cdot \mathrm{L}^{-1}$, respectively. Therefore, the mass concentrations of the $\mathrm{SO}_{4}^{2-}, \mathrm{Cr}^{6+}$ and $\mathrm{Cr}^{3+}$ in the simulated water samples were $816 \mathrm{mg} \cdot \mathrm{L}^{-1}, 10 \mathrm{mg} \cdot \mathrm{L}^{-1}$ and $20 \mathrm{mg} \cdot \mathrm{L}^{-1}$, respectively, with a $\mathrm{pH}$ value of 4.0 .

\subsection{Preparation Method of Immobilized Particles}

The immobilized particles were prepared by using the previous research results of the research group [19]. The mass percentage of $9 \%$ PVA and $1 \%$ sodium alginate were dissolved in distilled water and placed in a sealed container at room temperature at $25^{\circ} \mathrm{C}$. After $24 \mathrm{~h}$, the product was fully bloated and put into a thermostatic water bath. The product was heated at $90^{\circ} \mathrm{C}$ for 1.5 $\mathrm{h}$ and stirred continuously until it was bubble-free. The measured nano-Fe ${ }^{0}$ material and the corn cob powder were slowly added into the gel, fully stirred and evenly removed, and sealed and cooled to $37 \pm 1^{\circ} \mathrm{C}$ at room temperature. 1-2 The gel mixture was absorbed by peristaltic pump and directly dropped into $2 \% \mathrm{CaCl}_{2}$ saturated boric acid solution. During the process, the agitator was used for cross-linking at a stirring rate of $100 \mathrm{rpm}$. After $4 \mathrm{~h}$, take out the particles, rinse them with $0.9 \%$ normal saline, and 
then suck up the surface water, and reciprocate for 3 times. The particles were activated in an anaerobic environment for $12 \mathrm{~h}$ using an improved Starkey culture medium solution with no organic components. The immobilized particles were prepared by this method in subsequent experiments.

\subsection{Water Quality Monitoring Methods}

$\mathrm{SO}_{4}{ }^{2-}$ : barium chromate spectrophotometry; $\mathrm{Cr}^{6+}$ : diphenylcarbazide spectrophotometry; $\mathrm{Cr}^{3+}$ : potassium permanganate-diphenylcarbazide spectrophotometry; TFe: phenanthroline spectrophotometry; COD: Rapid digestion spectrophotometry; pH: glass electrode method [20].

\section{Results and Discussion}

\subsection{Single-Factor Experimental Study}

\subsubsection{Determination of SRB dosage}

According to the preparation method of immobilized particles mentioned above, 200 mesh corn cobs with $5 \%$ mass fraction were added into the mixture gel, stirred and cooled to room temperature evenly. Then, SRB microbial community fluids with mass fraction of $10 \%, 20 \%, 30 \%, 40 \%$ and $50 \%$ were added and fully stirred evenly for the preparation of 5 kinds of immobilized particles, which were then added into a series of conical bottles according to the ratio of solid to liquid 1:10, and each experiment was repeated for three times. Sampling was conducted regularly every day to determine the concentration of characteristic pollutants and control the amount of pollutant release, calculate the removal rate of pollutants, and draw images from the average value of repeated experiments, so as to seek the best SRB bacterial colony liquid input. The test results are shown in Fig. 1.

\subsubsection{The analysis of $\mathrm{SO}_{4}{ }^{2-}$ removal effect}

As shown in Fig. 1(a), with the extension of time, the removal rate of $\mathrm{SO}_{4}{ }^{2-}$ shows an obvious upward trend. When the SRB dosage was $10 \%, 20 \%, 30 \%, 40 \%$ and $50 \%$, respectively, the average removal rate of $\mathrm{SO}_{4}{ }^{2-}$ was $45.44 \%, 55.72 \%, 65.61 \%, 57.09 \%$ and $53.04 \%$, respectively. This is because when the dosage of SRB is low, too few strains cannot well adapt to the inhibition of its activity by the strongly acidic environment in the wastewater, resulting in its limited activity and its ability to dissimilate and reduce $\mathrm{SO}_{4}{ }^{2-}$ to form $\mathrm{S}^{2-}$ [21].However, when the dosage of SRB is too large, due to the competitive growth relationship among strains within the bacteria group, too many strains will make the competitive effect more intense and significant [22], thus reducing the metabolic activity of part of SRB, thus affecting the removal effect of $\mathrm{SO}_{4}{ }^{2-}$.

\subsubsection{The analysis of $\mathrm{Cr}^{6+}$ removal effect}

As shown in Fig. 1(b), the removal rate of $\mathrm{Cr}^{6+}$ shows an obvious rising trend with the extension of time. When the SRB dosage was $10 \%, 20 \%, 30 \%, 40 \%$ and $50 \%$, the average removal rate of $\mathrm{Cr}^{6+}$ was $72.86 \%, 71.14 \%, 73.01 \%, \quad 71.00 \%$ and $70.75 \%$, respectively. This is because when the dosage of SRB is low, the amount of biological organic carbon source used by the strain is limited, so the remaining unhydrolyzed corn cob can still be used as an adsorbent to adsorb and remove $\mathrm{Cr}^{6+}$. Therefore, the removal rate of $\mathrm{Cr}^{6+}$ is at a high level. However, when the SRB dosage is high, the $\mathrm{pH}$ value of the system is still in weak acidity, which is not conducive to the precipitation of chromium hydroxide. It has been reported that the appropriate $\mathrm{pH}$ value is the key to the effective removal of $\mathrm{Cr}^{6+}$ by SRB, and the slightly acidic solution will limit the growth of SRB, resulting in the reduction of $\mathrm{Cr}^{6+}$ removal rate [23]. In addition, it can be seen from Fig. 1(a) that when the SRB dosage is high, the removal effect of $\mathrm{SO}_{4}{ }^{2-}$ is poor, so there are less $\mathrm{H}_{2} \mathrm{~S}$ and $\mathrm{S}^{2-}$ free in the solution. However, $\mathrm{H}_{2} \mathrm{~S}$ and $\mathrm{Cr}^{6+}$ can undergo a redox reaction to convert $\mathrm{Cr}^{6+}$ to low toxicity $\mathrm{Cr}^{3+}$ [24]. $\mathrm{S}^{2-}$ can be combined with $\mathrm{Cr}^{6+}$ and $\mathrm{Cr}^{3+}$ to form metal sulfide precipitation. Therefore, the reduction of $\mathrm{H}_{2} \mathrm{~S}$ and $\mathrm{S}^{2-}$ also leads to a decrease in the $\mathrm{Cr}^{6+}$ removal rate.

\subsubsection{The analysis of $\mathrm{Cr}^{3+}$ removal effect}

As shown in Fig. 1(c), the removal rate of $\mathrm{Cr}^{3+}$ shows an obvious upward trend with the extension of time. When the SRB dosage was $10 \%, 20 \%, 30 \%, 40 \%$ and $50 \%$, respectively, the average removal rate of $\mathrm{Cr}^{3+}$ was $12.44 \%, 15.52 \%, 20.24 \%, 17.42 \%$ and $18.40 \%$,

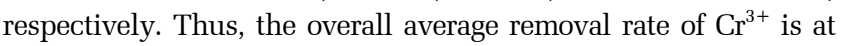
a low level, only about $20 \%$. This is because the $\mathrm{Cr}^{6+}$ in the wastewater will be reduced to $\mathrm{Cr}^{3+}$ by some reducing materials or microorganisms [25]. When the removal effect of $\mathrm{Cr}^{6+}$ is good, the amount of it will be reduced to $\mathrm{Cr}^{3+}$ is large. However, due to the limited adsorption capacity of the material to $\mathrm{Cr}^{3+}$, the removal effect is poor, namely, the better the removal effect of $\mathrm{Cr}^{6+}$ is, the worse the corresponding removal effect of $\mathrm{Cr}^{3+}$ will be. However, for $3 \#$, due to its best removal effect on $\mathrm{SO}_{4}{ }^{2-}$ and the presence of a large number of free $\mathrm{S}^{2-}$ in the wastewater, $\mathrm{Cr}^{3+}$ and its ability to form metal sulfide precipitation removal are enhanced, so its removal rates of $\mathrm{Cr}^{6+}$ and $\mathrm{Cr}^{3+}$ are at a high level.

\subsubsection{The analysis of $C O D$ release}

As shown in Fig. 1(d), with the extension of time, COD release shows a trend of first increasing, then decreasing and then increasing. This is due to the presence of some fine particles on the surface of the cob at the beginning of the reaction. These fine particles can be rapidly hydrolyzed into small molecular organic compounds in water. However, in the early stage, the activity of SRB is relatively low and the amount of carbon source used is limited, so a large number of organic compounds are accumulated and released into the water, resulting in a significant increase in COD release. Then, when SRB adapts to the wastewater environment, its metabolic activity is significantly enhanced and carbon source utilization rate is correspondingly increased, so COD shows an obvious downward trend. With the continuous progress of the reaction, the corn cob with a larger particle size began to hydrolyze, releasing more COD, so the COD release amount in the later period increased significantly. When the SRB dosage was $10 \%, 20 \%, 30 \%$, $40 \%$ and $50 \%$, respectively, the average COD release amount was $700.2 \mathrm{mg} \cdot \mathrm{L}^{-1}, 727.4 \mathrm{mg} \cdot \mathrm{L}^{-1}, 612.8 \mathrm{mg} \cdot \mathrm{L}^{-1}, 776 \mathrm{mg} \cdot \mathrm{L}^{-1}$ and $626 \mathrm{mg} \cdot \mathrm{L}^{-1}$, respectively. This is because when $\mathrm{SO}_{4}{ }^{2-}$ removal effect is good, $\mathrm{COD} / \mathrm{SO}_{4}{ }^{2-}$ should be at a higher level [26], and the COD release amount should be correspondingly higher, so the COD release amount of $4 \#$ and $2 \#$ particles is significant. For particles $1 \#$ and $5 \#$, due to the small dosage of SRB of particles $1 \#$ and large dosage of SRB of particles $5 \#$, and the limited capacity of using 

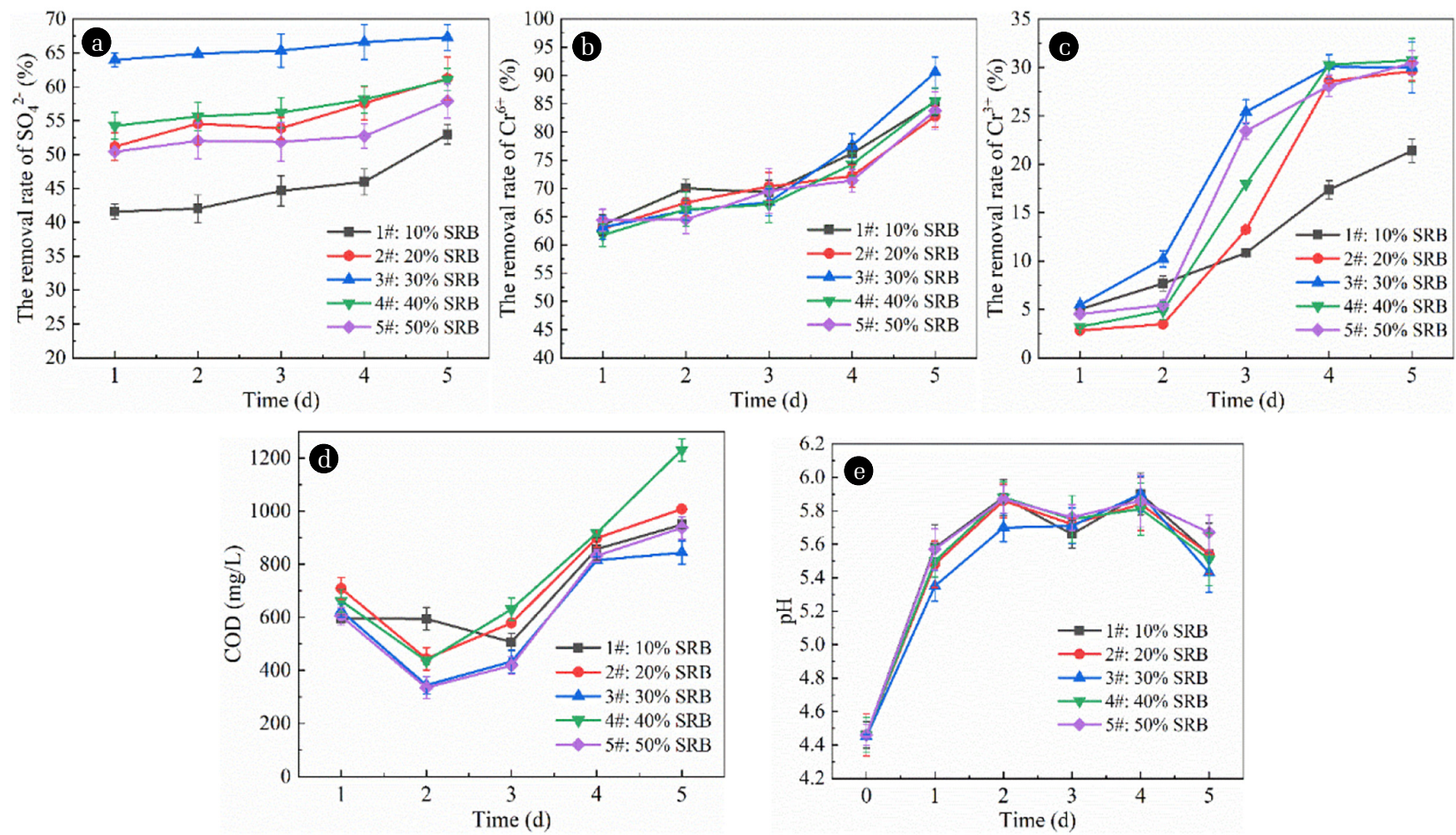

Fig. 1. Effect of SRB dosage on immobilized particles treatment of AMD. (a) Effect of SRB dosage on the removal of $\mathrm{SO}_{4}{ }^{2-}$ by immobilized particles. (b) Effect of SRB dosage on the removal of $\mathrm{Cr}^{6+}$ by immobilized particles. (c) Effect of SRB dosage on the removal of $\mathrm{Cr}^{3+}$ by immobilized particles. (d) Effect of SRB dosage on COD release of immobilized particles. (e) Effect of SRB dosage in immobilized particles on $\mathrm{pH}$ in $\mathrm{AMD}$.

carbon source in a small dosage of SRB, the COD amount of effluent of $5 \#$ is lower than $1 \#$. The removal effect of $3 \#$ particles on $\mathrm{SO}_{4}{ }^{2-}$ and $\mathrm{Cr}$ is good, indicating that the SRB activity in 3\# particles is strong, the COD consumed by SRB metabolism is high, and the COD released in water is relatively low.

\subsubsection{The analysis of $\mathbf{p H}$ effect}

As shown in Fig. 1(e), with the extension of time, $\mathrm{pH}$ shows a trend of fluctuation and slight decline in the later stage of rise. This is because the corn cob has not been massively hydrolyzed in the early stage of the reaction, and the active groups on the surface of the corn cob, such as hydroxyl, alcohol, carboxyl and amino groups, can adsorb $\mathrm{H}^{+}$to the surface of the corn cob [27, 28], so the $\mathrm{pH}$ significantly increased in the early stage. The hydrolyzed corn cob, as a carbon source, enhances the metabolic activity of SRB, which can release a certain alkalinity [29] during metabolism, contributing to the increase of $\mathrm{pH}$. However, the effect is not significant, so the $\mathrm{pH}$ is only maintained at a certain level. When the SRB dosage was $10 \%, 20 \%, 30 \%, 40 \%$ and $50 \%$ respectively, the average $\mathrm{pH}$ value of effluent was 5.72, 5.69, 5.62, 5.70 and 5.76, with little difference.

To sum up, by comparing the removal effects of the immobilized particles on $\mathrm{SO}_{4}{ }^{2-}, \mathrm{Cr}^{6+}$ and $\mathrm{Cr}^{3+}$ and the ability to improve COD release and $\mathrm{pH}$ of the 5 groups, and taking into account the changes of the indicators of the 5 groups, the optimal SRB dosage was finally selected as $30 \%$ in the test.

\subsubsection{Determination of Nano-Fe0 dosage}

According to the preparation method of immobilized particles mentioned above, 200 mesh corn cobs with mass fraction of $5 \%$ and nano- $\mathrm{Fe}^{0}$ with mass fraction of $1 \%, 2 \%, 3 \%, 4 \%$ and $5 \%$ were added into the mixture gel. Then the SRB microflora solution with mass fraction of $30 \%$ was added to prepare 5 kinds of immobilized particles. The prepared immobilized particles were placed in AMD and each experiment was repeated three times. Sampling was conducted regularly every day to determine the concentration of characteristic pollutants and control the amount of pollutant release, calculate the removal rate of pollutants, and draw images from the average value of repeated experiments in order to seek the best nano-Fe ${ }^{0}$ dosage. The test results are shown in Fig. 2.

\subsubsection{The analysis of $\mathrm{SO}_{4}{ }^{2-}$ removal effect}

As shown in Fig. 2(a), with the extension of time, the removal rate of $\mathrm{SO}_{4}{ }^{2-}$ shows an obvious upward trend. When the nano- $\mathrm{Fe}^{0}$ dosage was $1 \%, 2 \%, 3 \%, 4 \%$ and $5 \%$, the average $\mathrm{SO}_{4}{ }^{2-}$ removal rate was $79.35 \%, 90.62 \%, 93.32 \%, 85.53 \%$ and $74.28 \%$, respectively. This is because the nano- $\mathrm{Fe}^{0}$ particle size is so small that it can penetrate the cell wall and enter into the microbial cell, showing certain toxicity to microbial protease and inhibiting its metabolic activity [30]. Therefore, due to the large dosage of nano- $\mathrm{Fe}^{0}$ added to $5 \#$ particles, the excess nano- $\mathrm{Fe}^{0}$ in the system enters into the cell and has a strong inhibitory effect on SRB activity. However, because the dosage of $1 \#$ particle is too small, nano- $\mathrm{Fe}^{0}$ cannot 
play a good role in adsorption and reduction, and the SRB activity is low, so the $\mathrm{SO}_{4}{ }^{2-}$ removal effect is also at a low level. The dosage of nano- $\mathrm{Fe}^{0}$ in particles $2 \#, 3 \#$ and $4 \#$ was appropriate. The adsorption and reduction of nano-Fe ${ }^{0}$ promoted the growth of SRB, and the remaining nano- $\mathrm{Fe}^{0}$ did not produce toxicity to microbial protease. Therefore, the $\mathrm{SO}_{4}{ }^{2-}$ removal effect of particles $2 \#, 3 \#$ and $4 \#$ was significant, with an average removal rate of about $90 \%$. Studies have shown that the removal rate of $\mathrm{SO}_{4}{ }^{2-}$ in AMD by SRB in the expanded granular sludge bed reactor is $60.8 \%$ [31]. Previous research results showed that [32] the average removal rate of $\mathrm{SO}_{4}{ }^{2-}$ from the immobilized particles prepared with bagasse, medicinite and SRB was $70.13 \%$ at $\mathrm{pH}=4$. Compared with the above studies, the removal rate of $\mathrm{SO}_{4}{ }^{2-}$ of the five particles prepared under this condition was higher, indicating that the addition of nano- $\mathrm{Fe}^{0}$ to the immobilized particles was conducive to the growth of SRB.

\subsubsection{The analysis of $\mathrm{Cr}^{6+}$ removal effect}

As shown in Fig. 2(b), with the extension of time, the removal rate of $\mathrm{Cr}^{6+}$ shows an obvious rising trend, reaching nearly $100 \%$ removal rate after 12 hours. When the nano- $\mathrm{Fe}^{0}$ dosage was $1 \%$, $2 \%, 3 \%, 4 \%$ and $5 \%$, the average removal rate of $\mathrm{Cr}^{6+}$ within 24 hours was $73.31 \%, 73.99 \%, 75.52 \%, 76.65 \%$ and $78.16 \%$, respectively. This is because with the increase of nano- $\mathrm{Fe}^{0}$ dosage, more raw materials enhance their ability to reduce $\mathrm{Cr}^{6+}$ and transform it into $\mathrm{Cr}^{3+}$, so the removal effect of $\mathrm{Cr}^{6+}$ is significantly improved. However, compared with the 5 groups of particles, there was no significant difference in the removal rate of $\mathrm{Cr}^{6+}$, which further proves that nano- $\mathrm{Fe}^{0}$ has extremely strong activity, and a small dosage of nano- $\mathrm{Fe}^{0}$ can achieve excellent removal effect of $\mathrm{Cr}^{6+}$.

\subsubsection{The analysis of $\mathrm{Cr}^{3+}$ removal effect}

As shown in Fig. 2(c), the removal rate of $\mathrm{Cr}^{3+}$ shows an obvious upward trend with the extension of time. The average removal rate of $\mathrm{Cr}^{3+}$ was $74.07 \%, 75.98 \%, 80.93 \%, 81.51 \%$ and $76.07 \%$, respectively, when the nano-Fe ${ }^{0}$ dosage was $1 \%, 2 \%, 3 \%, 4 \%$ and $5 \%$. This is due to the $1 \#, 2 \#$ particles nano- $\mathrm{Fe}^{0}$ dosing quantity is less, the adsorption activity of $\mathrm{Cr}^{3+}$, points less, so the $\mathrm{Cr}^{3+}$, adsorption ability is poorer, at the same time, the reduce of nano- $\mathrm{Fe}^{0}$ dosing quantity $\mathrm{SO}_{4}{ }^{2}$ - removal effect is reduced, thus reduce the water free of $\mathrm{S}^{2-}$ content, $\mathrm{Cr}^{3+}$, and metal sulfide precipitation probability corresponding lower formation, therefore, the removal rate of $\mathrm{Cr}^{3+}$ is low. For $5 \#$ particles, due to the biological toxic effect of nano- $\mathrm{Fe}^{0}$, the introduction of too much nano- $\mathrm{Fe}^{0}$ will inhibit the metabolic activity of SRB and reduce the probability of precipitation removal of $\mathrm{Cr}^{3+}$, so its removal effect on $\mathrm{Cr}^{3+}$ is weaker than that of $3 \#$ and $4 \#$ particles.

\subsubsection{The analysis of COD release}

As shown in Fig. 2(d), with the extension of time, COD release shows a trend of significant rise and then stabilization. When the nano- $\mathrm{Fe}^{0}$ dosage was $1 \%, 2 \%, 3 \%, 4 \%$ and $5 \%$, the average COD release was $1,336.6 \mathrm{mg} \cdot \mathrm{L}^{-1}, 1,311.2 \mathrm{mg} \cdot \mathrm{L}^{-1}, 1,277.4 \mathrm{mg} \cdot \mathrm{L}^{-1}, 1,254.6$ $\mathrm{mg} \cdot \mathrm{L}^{-1}$ and $1,219.4 \mathrm{mg} \cdot \mathrm{L}^{-1}$, respectively. This indicates that there is a certain negative correlation between the dosage of nano- $\mathrm{Fe}^{0}$ and the amount of COD release. Although the cause of this abnormal phenomenon is mainly due to the nano-Fe ${ }^{0}$ decomposition of corn cob has strong catalytic effect, but when nano- $\mathrm{Fe}^{0}$ dosing quantity is higher, the nano- $\mathrm{Fe}^{0}$ destroys the internal structure of corn cobs,
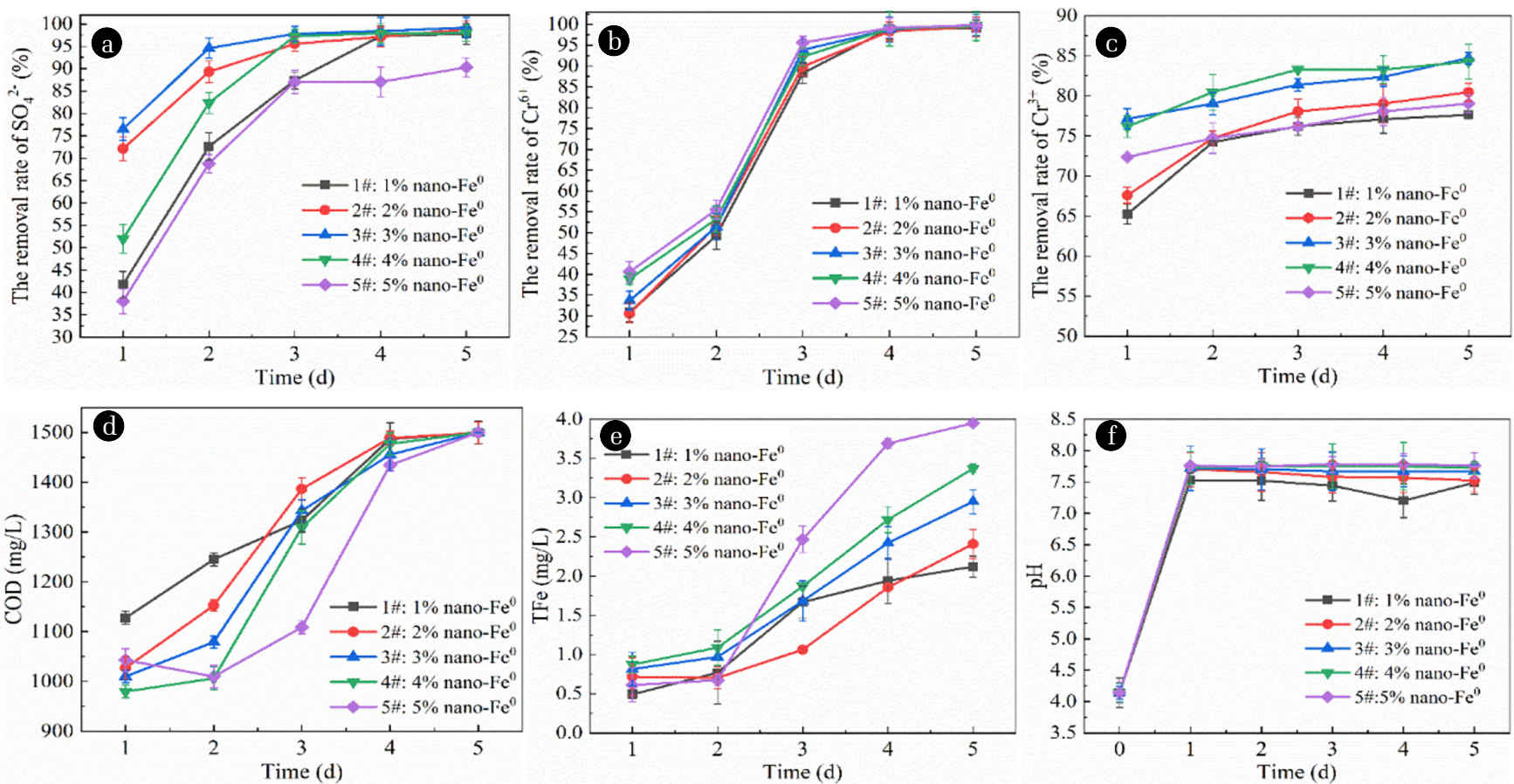

Fig. 2. Effect of nano- $\mathrm{Fe}^{0}$ dosage on immobilized particle treatment of $\mathrm{AMD}$. (a) Effect of nano-Fe ${ }^{0}$ dosage on the removal of $\mathrm{SO}_{4}{ }^{2-}$ by immobilized particles. (b) Effect of nano-Fe ${ }^{0}$ dosage on the removal of $\mathrm{Cr}^{6+}$ by immobilized particles. (c) Effect of nano-Fe ${ }^{0}$ dosage on the removal of $\mathrm{Cr}^{3+}$ by immobilized particles. (d) Effect of nano- $\mathrm{Fe}^{0}$ dosage on COD release of immobilized particles. (e) Effect of nano-Fe ${ }^{0}$ dosage on TFe release of immobilized particles. (f) Effect of nano- $\mathrm{Fe}^{0}$ dosage in immobilized particles on $\mathrm{pH}$ in AMD. 
make its hydrolysis not well generated for SRB small molecule organic matter [33], so the content of COD in water decreases. At the same time, when the dosage of nano- $\mathrm{Fe}^{0}$ is high, due to its certain biotoxicity, the activity of hydrolyzed microorganisms is inhibited and the decomposition ability is weakened, so the COD release shows a downward trend.

\subsubsection{The analysis of TFe release}

As shown in Fig. 2(e), with the extension of time, TFe release shows a trend of continuous increase. When the nano- $\mathrm{Fe}^{0}$ dosage was $1 \%, 2 \%, 3 \%, 4 \%$ and $5 \%$, the average TFe release was 1.40 $\mathrm{mg} \cdot \mathrm{L}^{-1}, 1.35 \mathrm{mg} \cdot \mathrm{L}^{-1}, 1.77 \mathrm{mg} \cdot \mathrm{L}^{-1}, 1.98 \mathrm{mg} \cdot \mathrm{L}^{-1}$ and $2.28 \mathrm{mg} \cdot \mathrm{L}^{-1}$, respectively. This is because at the initial stage of the reaction, with the increase of nano- $\mathrm{Fe}^{0}$ dosage, the degree of the reaction with $\mathrm{H}^{+}$in the AMD is correspondingly enhanced, and more iron ions are generated and free in the AMD, so the release amount of TFe in the solution increases. However, as the reaction progresses, the free iron ions will react with $\mathrm{OH}^{-}$in the solution to form hydroxide precipitation, reducing or leveling the TFe release in the solution. This conclusion is consistent with the research results of Homhoul et al. [34]. Homhoul et al. [34] showed that the formation of iron ions by the oxidation of $\mathrm{Fe}^{0}$ at the initial stage of the reaction would lead to an increase in the content of iron ions in the AMD. The iron ions generated could react with the reduction product $\mathrm{OH}^{-}$of water, and precipitate from the waste water to reduce the concentration of iron ions.

\subsubsection{The analysis of $\mathrm{pH}$ effect}

As shown in Fig. 2(f), with the extension of time, $\mathrm{pH}$ value increases rapidly in the early stage, but changes in the later stage by a small extent, showing a fluctuating state. This is because nano- $\mathrm{Fe}^{0}$ can react quickly with $\mathrm{H}^{+}$in the early stage, significantly raising $\mathrm{pH}$ to neutral level. Then, due to the decrease of $\mathrm{H}^{+}$content in AMD, the reaction degree was weakened and the improvement effect was not significant. When the nano- $\mathrm{Fe}^{0}$ dosage was $1 \%, 2 \%, 3 \%$, $4 \%$ and $5 \%$, respectively, the average $\mathrm{pH}$ value of the effluent was $7.45,7.60,7.72,7.75$ and 7.77 , with little difference. Thus, it can be seen that nano- $\mathrm{Fe}^{0}$ has extremely strong activity, and a small dosage of nano- $\mathrm{Fe}^{0}$ can achieve a good effect on $\mathrm{pH}$, increasing the $\mathrm{pH}$ value from 4.0 to neutral.

To sum up, by comparing the removal effects of the immobilized particles on $\mathrm{SO}_{4}{ }^{2-}, \mathrm{Cr}^{6+}$ and $\mathrm{Cr}^{3+}$, as well as the lifting capacity of COD and TFe release and $\mathrm{pH}$ of the 5 groups, and taking into account the changes of the 6 groups of indicators, the optimal dosage of nano- $\mathrm{Fe}^{0}$ was selected as $3 \%$ in the final test.

\subsubsection{Determination of corn cob particle size}

According to the preparation method of immobilized particles mentioned above, 60 mesh, 100 mesh and 200 mesh cobs with mass fraction of $5 \%$ and $3 \%$ nano- $\mathrm{Fe}^{0}$ were added into the mixture gel respectively. Then the SRB microflora solution with mass fraction of $30 \%$ was added to prepare three kinds of immobilized particles. The prepared immobilized particles were placed in AMD and each experiment was repeated three times. Sampling was conducted regularly every day to determine the concentration of characteristic pollutants and control the amount of pollutant release, calculate the removal rate of pollutants, and draw images from the average value of repeated experiments to seek the best corn cob particle size. The test results are shown in Fig. 3.

\subsubsection{The analysis of $\mathrm{SO}_{4}{ }^{2-}$ removal effect}

As shown in Fig. 3(a), with the extension of time, the removal rate of $\mathrm{SO}_{4}^{2-}$ shows a significant upward trend. When the cob particle size was 60, 100 and 200 mesh, the average $\mathrm{SO}_{4}{ }^{2-}$ removal rate was $92.32 \%, 90.74 \%$ and $93.42 \%$, respectively. It can be seen that the removal rate of $\mathrm{SO}_{4}{ }^{2-}$ decreased first and then increased with the decrease of corn cob particle size. The removal of $\mathrm{SO}_{4}{ }^{2-}$ by the three particles is mainly dependent on the SRB metabolism of $\mathrm{SO}_{4}{ }^{2-}$ to produce $\mathrm{S}^{2-}$. It has been reported that $\mathrm{SRB}$ can convert sulfate into sulfide using organic matter under anaerobic conditions [35]. The results of previous studies [36] showed that in the immobilized particles filled with corn cob, SRB and salt-modified Wheat meal stone, the hydrolyzed products of corn cob could be used for SRB growth. When the removal area of $\mathrm{SO}_{4}{ }^{2-}$ is stable, the removal rate of the three kinds of particles has a small difference. The main reason for this difference is that when the grain size of the corn cob is large, there are pores inside the corn cob with large grain size, and part of $\mathrm{SO}_{4}{ }^{2-}$ will diffuse into the void. When the particle size of the corn cob decreased, the internal macropores of the corn cob decreased, and the removal of $\mathrm{SO}_{4}{ }^{2-}$ only depended on SRB metabolism. When the grain size of the corn cob is very small, the inner hole of the corn cob is easy to block, but the corn cob with very small grain size is easy to hydrolyze, which makes the COD content in the water higher and provides sufficient carbon source for the growth of SRB. Therefore, the metabolic activity of SRB is strong, so the $\mathrm{SO}_{4}{ }^{2-}$ removal effect is better.

\subsubsection{The analysis of $\mathrm{Cr}^{6+}$ removal effect}

As shown in Fig. 3(b), the removal rate of $\mathrm{Cr}^{6+}$ shows a significant upward trend with the extension of time. $\mathrm{The}^{\mathrm{Cr}}{ }^{6+}$ removal rate was $97.95 \%, 97.53 \%$ and $97.84 \%$ when the cob particle size was 60, 100 and 200 mesh, respectively. It can be seen that the removal rate of $\mathrm{Cr}^{6+}$ decreased slightly with the decrease of corn cob particle size. This is because when the corn cob particle size is large, the hydrolysis of the corn cob is not sufficient, and the unhydrolyzed corn cob has a certain adsorption effect on $\mathrm{Cr}^{6+}$, so the removal rate of $\mathrm{Cr}^{6+}$ is slightly higher. It is reported that active groups such as hydroxyl group, alcohol group, carboxyl group and amino group in corn cob can be used as adsorbents for heavy metal ions $[27,28]$. When the particle size of the corn cob decreases, the adsorption capacity of the corn cob decreases due to more thorough hydrolysis, but the organic matter formed by hydrolysis can better promote the metabolic activity of SRB and generate more $\mathrm{S}^{2-}$ and form precipitation with heavy metals. Therefore, the removal effect of the corn cob with small particle size is also at a good level.

\subsubsection{The analysis of $\mathrm{Cr}^{3+}$ removal effect}

As shown in Fig. 3(c), the removal rate of the $\mathrm{Cr}^{3+}$ shows a significant upward trend with the extension of time. The $\mathrm{Cr}^{3+}$ removal rate was $82.09 \%, 79.46 \%$ and $77.59 \%$ when the cob particle size was 60, 100 and 200 mesh, respectively. It can be seen that the removal rate of $\mathrm{Cr}^{3+}$ shows a certain downward trend with the decrease of corn cob particle size. The removal of $\mathrm{Cr}^{3+}$ by the three kinds of particles mainly depends on SRB metabolism to produce $\mathrm{S}^{2-}, \mathrm{S}^{2-}$ 

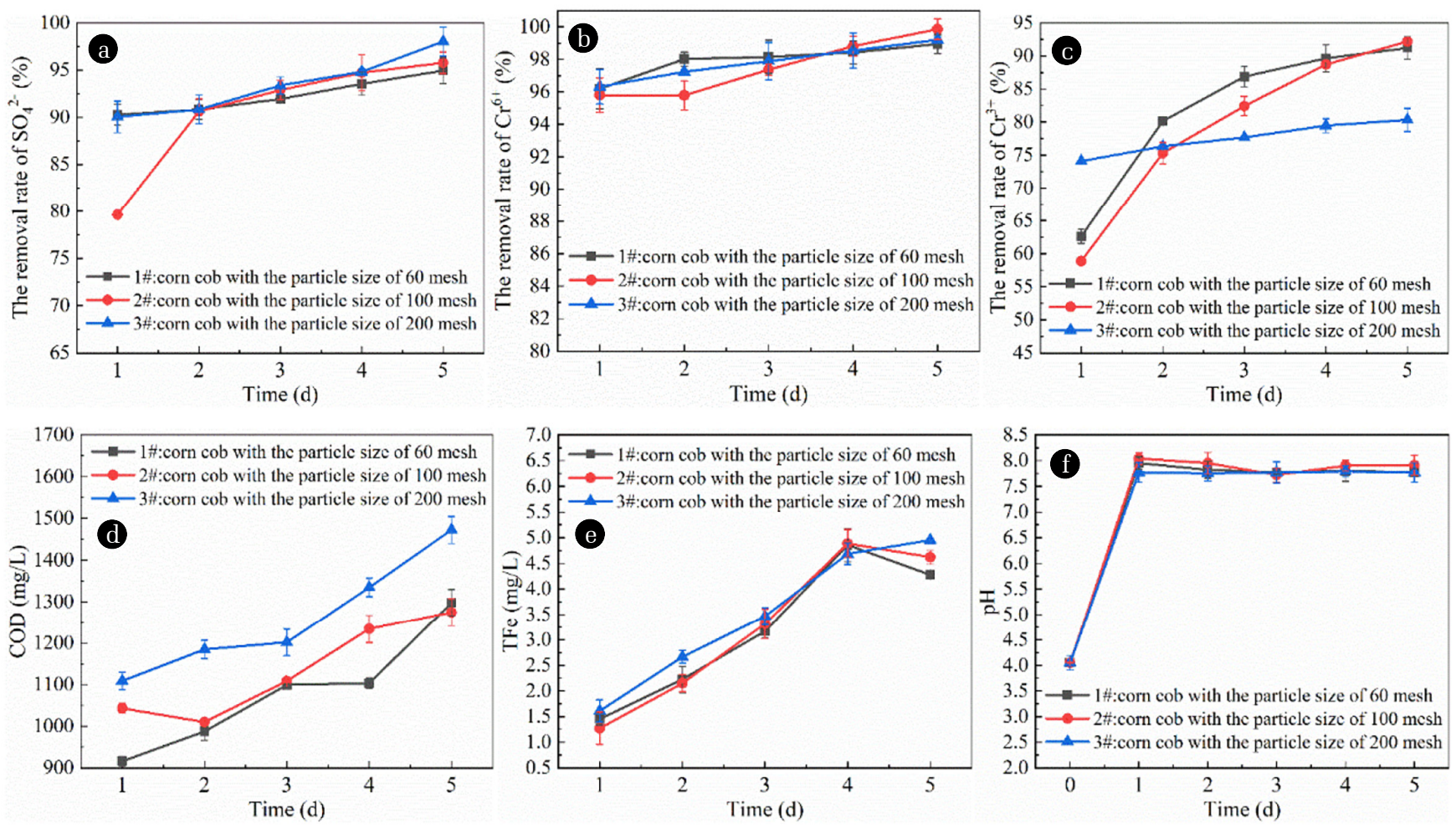

Fig. 3. Influence of corn cob particle size on immobilized particle treatment of $\mathrm{AMD}$. (a) Effect of corn cob particle size on removal of $\mathrm{SO}_{4}{ }^{2-}$ by immobilized particles. (b) Effect of corn cob particle size on the removal of $\mathrm{Cr}^{6+}$ by immobilized particles. (c) Effect of corn cob particle size on the removal of $\mathrm{Cr}^{3+}$ by immobilized particles. (d) Effect of corn cob particle size on COD release of immobilized particles. (e) Effect of corn cob particle size on TFe release of immobilized particles. (f) Effect of corn cob particle size in immobilized particles on $\mathrm{pH}$ in $\mathrm{AMD}$.

and $\mathrm{Cr}^{3+}$ form precipitation, so that $\mathrm{Cr}^{3+}$ is removed. Secondly, the active groups on the surface of corn cob can also adsorb $\mathrm{Cr}^{3+}$. When the grain size of the corn cob is large, the corn cob is not completely hydrolyzed. The active groups on the surface of the corn cob, such as hydroxyl, alcohol, carboxyl and amino groups [27, 28], can adsorb $\mathrm{Cr}^{3+}$.The hydrolyzed corn cob provides carbon source for SRB and promotes the formation of sulfide precipitation between $\mathrm{Cr}^{3+}$ and $\mathrm{S}^{2-}$, so the removal effect of $\mathrm{Cr}^{3+}$ is better. When the particle size of the corn cob decreases, the removal of $\mathrm{Cr}^{3+}$ mainly depends on the formation of sulfide precipitation. At the same time, small particles of the corn cob will block the particle channel, affecting the ion mass transport, so the removal effect is reduced.

\subsubsection{The analysis of COD release}

As shown in Fig. 3(d), COD release shows a certain upward trend with the extension of time. When the grain size of corn cob was 60, 100 and 200 meshes, the average COD release was 1,080.2 $\mathrm{mg} \cdot \mathrm{L}^{-1}, 1,134.2 \mathrm{mg} \cdot \mathrm{L}^{-1}$ and $1,260.6 \mathrm{mg} \cdot \mathrm{L}^{-1}$, respectively. It can be seen that the average COD release shows an increasing trend with the decrease of corn cob particle size. This is because the cob with oversize particle size is more prone to hydrolyze under the catalytic action of nano-Fe ${ }^{0}$, releasing more organic matter into the water, so the COD release amount is higher.

\subsubsection{The analysis of TFe release}

As shown in Fig. 3(e), with the extension of time, TFe release shows a certain upward trend. When the cob particle size was 60, 100 and 200 mesh, the average TFe release was $3.198 \mathrm{mg} \cdot \mathrm{L}^{-1}$, $3.250 \mathrm{mg} \cdot \mathrm{L}^{-1}$ and $3.478 \mathrm{mg} \cdot \mathrm{L}^{-1}$, respectively. It can be seen that the average TFe release shows an overall trend of increasing with the decrease of corn cob particle size. This is because when the particle size of corn cob is small, its hydrolysis in AMD is more thorough, and the SRB activity is significantly increased due to the higher COD content. As the reduction of $\mathrm{SO}_{4}{ }^{2-}$ by $\mathrm{SRB}$ requires the participation of reducing electrons, nano- $\mathrm{Fe}^{0}$ will release a large amount of $\mathrm{Fe}^{2+}$ and $\mathrm{Fe}^{3+}$ into the water body while replenishing the reduced electrons [37], resulting in a high TFe content.

\subsubsection{The analysis of $\mathrm{pH}$ effect}

As shown in Fig. 3(f), $\mathrm{pH}$ value shows a certain upward trend with the extension of time. When the grain size of corn cob was 60,100 and 200 mesh, the average $\mathrm{pH}$ value of water was 7.83 , 7.90 and 7.77, respectively, with little difference, and the water output was in a weakly alkaline state. This further indicates that nano- $\mathrm{Fe}^{0}$ is highly active and can rapidly increase the $\mathrm{pH}$ value of the wastewater to a neutral state. However, because it is prone to corrosion in acidic water environment, hydroxide precipitation or fine flocculants are generated and dispersed in the water, the wastewater showed a certain weak alkalinity [38].

To sum up, by comparing the removal effects of immobilized particles on $\mathrm{SO}_{4}{ }^{2-}, \mathrm{Cr}^{6+}$ and $\mathrm{Cr}^{3+}$, and the ability to improve COD 
release and $\mathrm{pH}$, considering that the COD and TFe release should not be too large, and considering the changes of the six groups of indicators, the optimal particle size of corn cob was finally selected as 60 mesh.

\subsubsection{Determination of cob dosage}

According to the preparation method of immobilized particles mentioned above, 60 mesh corn cobs with mass fraction of $1 \%$, $3 \%$ and $5 \%$ and nano- $\mathrm{Fe}^{0}$ with mass fraction of $3 \%$ were added to the mixture gel respectively. Then the SRB microflora solution with mass fraction of $30 \%$ was added to prepare three kinds of immobilized particles. The prepared immobilized particles were placed in AMD and each experiment was repeated three times. Sampling was conducted regularly every day to determine the concentration of characteristic pollutants and control the amount of pollutant release, calculate the removal rate of pollutants, and draw images from the average value of repeated experiments to seek the best corn cob dosage. The test results are shown in Fig. 4

\subsubsection{The analysis of $\mathrm{SO}_{4}{ }^{2-}$ removal effect}

As shown in Fig. 4(a), with the extension of time, the removal rate of $\mathrm{SO}_{4}^{2-}$ shows a significant upward trend. When the cob loading was $1 \%, 3 \%$ and $5 \%$, the average $\mathrm{SO}_{4}{ }^{2-}$ removal rate was $77.81 \%$, $81.03 \%$ and $81.31 \%$, respectively. It can be seen that the removal rate of $\mathrm{SO}_{4}{ }^{2-}$ shows an increasing trend with the increase of corn cob dosage. This is because with the increase of the dosage of corn cob added, the hydrolysis of corn cob will be further enhanced under the catalytic action of nano- $\mathrm{Fe}^{0}$, and the amount of available carbon source of SRB is sufficient, so the $\mathrm{SO}_{4}{ }^{2-}$ removal rate will be improved. However, when the added dosage of corn cob continues to increase, more organic matter will cause secondary pollution of water body. Meanwhile, due to the limited metabolic capacity of SRB, the $\mathrm{SO}_{4}^{2-}$ removal rate does not increase significantly. Das $\mathrm{B}$ et al. [39] analyzed the influence of $\mathrm{COD} / \mathrm{SO}_{4}{ }^{2-}$ on the removal of sulfate from SRB. The results showed that when $\mathrm{COD} / \mathrm{SO}_{4}{ }^{2-}=$ 1 and 2, the average removal of $\mathrm{SO}_{4}{ }^{2-}$ was $61 \%$ and $77 \%$, respectively, and when $\mathrm{COD} / \mathrm{SO}_{4}{ }^{2-}=4$, the maximum removal rate of $\mathrm{SO}_{4}{ }^{2-}$ was 99\%.It has been reported that the removal efficiency of $\mathrm{SO}_{4}^{2-}$ increases with the increase of $\mathrm{COD} / \mathrm{SO}_{4}{ }^{2-}$, and decreases with the further increase of $\mathrm{COD} / \mathrm{SO}_{4}{ }^{2-}$ after reaching its maximum value [39-41] The results of this study are consistent with the above reports.

\subsubsection{The analysis of $\mathrm{Cr}^{6+}$ removal effect}

As shown in Fig. 4(b), the removal rate of $\mathrm{Cr}^{6+}$ shows a significant upward trend with the extension of time. The average removal rate of $\mathrm{Cr}^{6+}$ was $99.67 \%, 99.78 \%$ and $99.82 \%$, respectively, when the dosage of corn cob was $1 \%, 3 \%$ and $5 \%$. It can be seen that the removal rate of $\mathrm{Cr}^{6+}$ shows a slightly increased trend with the increase of the dosage of corn cob added, with little difference. The removal rate of the three groups of grain could reach more than $99 \%$. This is because nano- $\mathrm{Fe}^{0}$ has strong reductibility, which can rapidly reduce the $\mathrm{Cr}^{6+}$ in water to $\mathrm{Cr}^{3+}$, and then remove it by precipitation or adsorption. Compared with that, the adsorption effect of corn cob is weak, so the dosage of adding corn cob has little influence on the removal of $\mathrm{Cr}^{6+}$.

3.1.4.3. The analysis of $\mathrm{Cr}^{3+}$ removal effect

As shown in Fig. 4(c), the removal rate of $\mathrm{Cr}^{3+}$ shows a significant
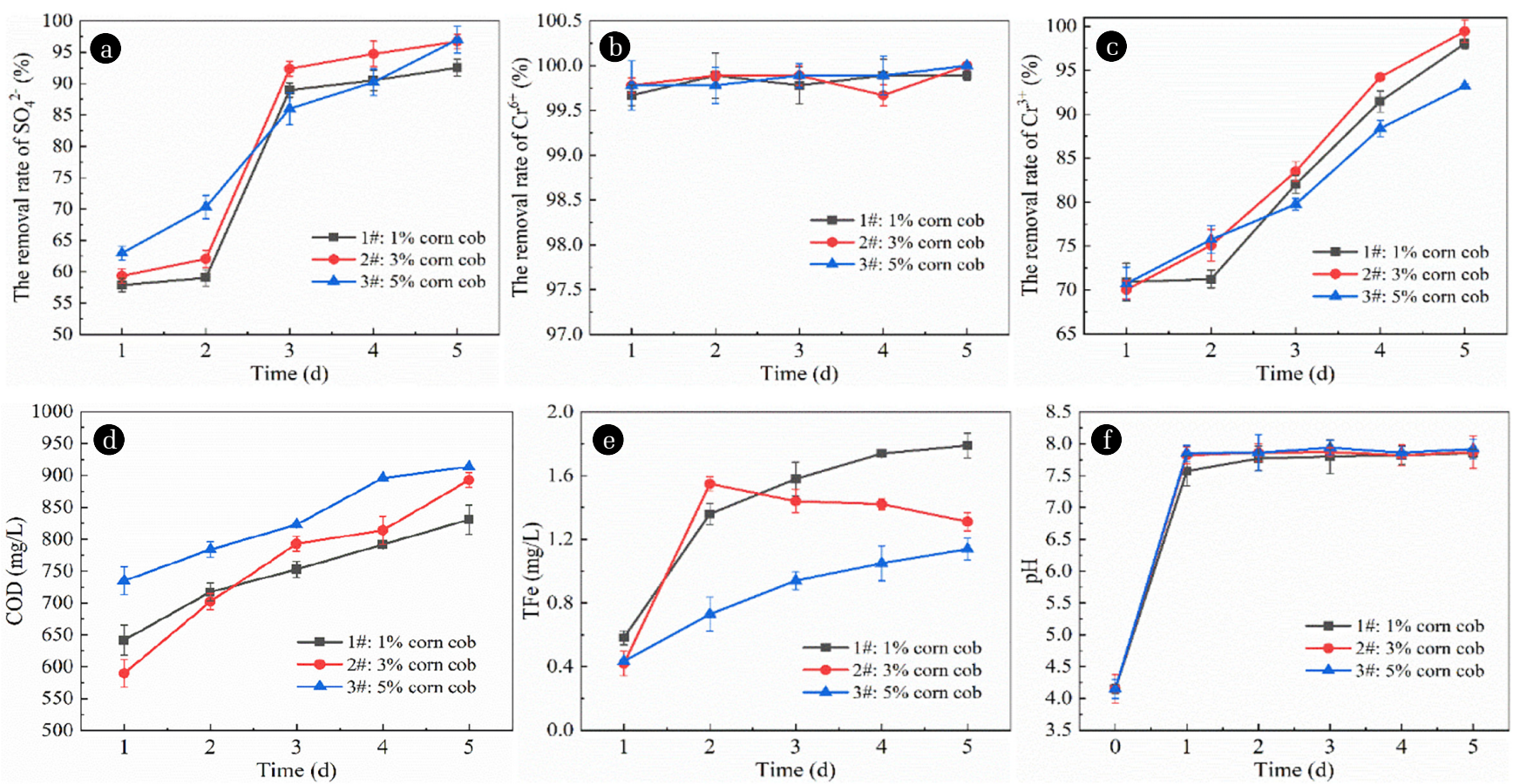

Fig. 4. Effect of corn cob dosage on immobilized granules treatment of $\mathrm{AMD}$. (a) Effect of corn cob dosage on the removal of $\mathrm{SO}_{4}{ }^{2-}$ by immobilized particles. (b) Effect of corn cob dosage on the removal of $\mathrm{Cr}^{6+}$ by immobilized particles. (c) Effect of corn cob dosage on the removal of $\mathrm{Cr}^{3+}$ by immobilized particles. (d) Effect of corn cob dosage on COD release of immobilized particles. (e) Effect of corn cob dosage on TFe release of immobilized particles. ( $f$ ) Effect of corn cob dosage in immobilized particles on pH in AMD. 
upward trend with the extension of time. The average removal rate of $\mathrm{Cr}^{3+}$ was $82.74 \%, 84.45 \%$ and $81.57 \%$ when the cob loading was $1 \%, 3 \%$ and $5 \%$, respectively. It can be seen that the removal rate of $\mathrm{Cr}^{3+}$ shows a trend of first increasing and then decreasing with the increase of cob dosage. This is because under the catalysis of nano- $\mathrm{Fe}^{0}$, more corn cobs can provide more carbon sources for SRB, and SRB is more active, which can release more $\mathrm{S}^{2-}$ and $\mathrm{Cr}^{3+}$ to form precipitation, so the removal rate is increased. In addition, with the increase of corn cob dosage, its ability to adsorb $\mathrm{Cr}^{3+}$ as an adsorbent was also enhanced, which also contributed to the removal rate to some extent. However, when the dosage of corn cob continues to increase, due to the limited capacity of SRB to utilize carbon sources, the COD content in water is relatively high. Relevant studies have shown that a high carbon-sulfur ratio inhibits the growth activity of SRB [42], and the content of $\mathrm{S}^{2-}$ generated by reduction decreases. Therefore, the removal efficiency of $\mathrm{Cr}^{3+}$ precipitation decreases and the removal effect becomes worse.

\subsubsection{The analysis of COD release}

As shown in Fig. 4(d), COD release shows a certain upward trend with the extension of time. When the dosage of corn cob was $1 \%, 3 \%$ and $5 \%$, the average COD release amount was $746.8 \mathrm{mg} \cdot \mathrm{L}^{-1}$, $758.2 \mathrm{mg} \cdot \mathrm{L}^{-1}$ and $830.4 \mathrm{mg} \cdot \mathrm{L}^{-1}$, respectively. It can be seen that the COD release amount presents an increasing trend with the increase of cob dosage. This is because under the catalytic action of nano-Fe ${ }^{0}$, more corn cob hydrolyzation will release a large amount of organic matter, while SRB's ability to utilize carbon source is limited, so the COD content of the effluent is relatively high.

\subsubsection{The analysis of TFe release}

As shown in Fig. 4(e), with the extension of time, TFe release shows a certain upward trend. When the dosage of corn cob was $1 \%, 3 \%$ and $5 \%$, the average TFe release amount was $1.410 \mathrm{mg} \cdot \mathrm{L}^{-1}$, $1.228 \mathrm{mg} \cdot \mathrm{L}^{-1}$ and $0.858 \mathrm{mg} \cdot \mathrm{L}^{-1}$, respectively. Therefore, TFe release shows a decreasing trend with the increase of cob dosage. This is because with the increase of corn cob dosage, it has a good adsorption effect on $\mathrm{H}^{+}$in wastewater, and the process of SRB dissimilar reduction of $\mathrm{SO}_{4}{ }^{2-}$ also releases alkalinity. Therefore, the free $\mathrm{OH}^{-}$in the water can form precipitation and deposit on the surface of particles with $\mathrm{Fe}^{2+}$ and $\mathrm{Fe}^{3+}$ generated by the hydrolysis of nano- $\mathrm{Fe}^{0}$, so the $\mathrm{TFe}$ release in the water is reduced.

\subsubsection{The analysis of $\mathrm{pH}$ effect}

As shown in Fig. 4(f), pH value shows a certain upward trend with the extension of time. When the cob dosage was $1 \%, 3 \%$ and $5 \%$, the average $\mathrm{pH}$ value of water was $7.77,7.86$ and 7.90 , respectively. It can be seen that the $\mathrm{pH}$ value of water shows a certain trend of increasing with the increase of cob dosage. This is because, on the one hand, with the increase of the dosage of corn cob, its adsorption capacity of $\mathrm{H}^{+}$was enhanced. On the other hand, more cobs cause the SRB metabolism to release more alkalinity, thus increasing the $\mathrm{pH}$.

To sum up, by comparing the removal effects of immobilized particles on $\mathrm{SO}_{4}{ }^{2-}, \mathrm{Cr}^{6+}$ and $\mathrm{Cr}^{3+}$, as well as the lifting capacity of COD release and $\mathrm{pH}$ of the 3 groups, considering that the COD and TFe release should not be too large, and considering the changes of the 6 groups of indicators, the optimal dosage of corn cob was finally selected as $3 \%$.

\subsection{Orthogonal Experimental Study}

Based on the composition of immobilized particles in the previous study, the orthogonal test of $\mathrm{L}_{9}\left(3^{4}\right)$ was carried out by selecting three levels of four factors according to the single factor test results, which were SRB dosage of $20 \%, 30 \%$ and $40 \%$, nano- $\mathrm{Fe}^{0}$ dosage of $2 \%, 3 \%$ and $4 \%$, corn cob particle size of 60 mesh, 100 mesh and 200 mesh, corn cob dosage of 1\%, 3\% and 5\%. Immobilized particles were prepared according to the orthogonal experimental design, and immobilized particles were placed in AMD to determine the indicators of characteristic pollutants. Three replicates were performed for each experiment, and the average value of the replicates was taken for the analysis of the results, as shown in Table 1. By means of range analysis, the optimal ratio of SRB bacterial liquid, nano- $\mathrm{Fe}^{0}$ and corn cob in immobilized particles was determined.

\subsubsection{Analysis of $\mathrm{SO}_{4}{ }^{2-}$ test result}

The greater the range of a certain influencing factor, the greater the influence on the experimental results. As can be seen from table S2, the influence of the four factors on the removal of $\mathrm{SO}_{4}{ }^{2-}$ is not significant. According to the range of table S1, the order of influence on $\mathrm{SO}_{4}{ }^{2-}$ removal rate is: $\mathrm{A}>\mathrm{D}>\mathrm{C}>\mathrm{B}$. Therefore, according to the mean size, the optimal combination of factors to determine the $\mathrm{SO}_{4}{ }^{2-}$ removal rate is $\mathrm{A}_{3} \mathrm{~B}_{3} \mathrm{C}_{2} \mathrm{D}_{2}$, that is, the SRB dosage is $40 \%$, the nano- $\mathrm{Fe}^{0}$ dosage is $4 \%$, the corn cob size is 100 mesh, and the corn cob dosage is $3 \%$. The $\mathrm{SO}_{4}{ }^{2-}$ removal rate of particles is the best under this composition ratio.

\subsubsection{Analysis the experiment results of $\mathrm{Cr}^{6+}$}

It can be seen from table $\mathrm{S} 4$ that the four factors have insignificant effects on the removal of $\mathrm{Cr}^{6+}$. According to the range of table $\mathrm{S} 3$, the order of influence on the removal rate of $\mathrm{Cr}^{6+}$ is $\mathrm{D}>$ $\mathrm{B}>\mathrm{A}>\mathrm{C}$. Therefore, according to the mean value, the optimal combination of factors to determine the $\mathrm{Cr}^{6+}$ removal rate is $\mathrm{A}_{2} \mathrm{~B}_{2} \mathrm{C}_{1} \mathrm{D}_{3}$, that is, the SRB is $30 \%$, the nano- $\mathrm{Fe}^{0}$ is $3 \%$, the corn

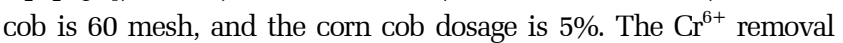
rate of particles is the best under this composition ratio.

\subsubsection{Analysis the experiment results of $\mathrm{Cr}^{3+}$}

It can be seen from table $\mathrm{S} 6$ that the four factors have insignificant effects on the removal of $\mathrm{Cr}^{3+}$. According to the range of table

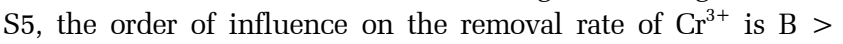
$\mathrm{C}>\mathrm{A}>\mathrm{D}$. Therefore, according to the mean size, the optimal combination of factors to determine the $\mathrm{Cr}^{3+}$ removal rate is $\mathrm{A}_{1} \mathrm{~B}_{3} \mathrm{C}_{2} \mathrm{D}_{2}$, that is, SRB is $20 \%$, nano-Fe ${ }^{0}$ is $4 \%$, corn cob is 100 mesh, and the corn cob dosage is $3 \%$. The $\mathrm{Cr}^{3+}$ removal rate of particles is the best under this composition ratio.

\subsubsection{Analysis the experiment results of COD}

It can be seen from table S8 that, among the four factors, SRB has a significant influence on COD released by particles. According to the range of table S7, the order of influence on COD release is: $\mathrm{A}>\mathrm{C}>\mathrm{D}>\mathrm{B}$. Therefore, the optimal combination of factors to determine the COD release amount according to the mean value is $\mathrm{A}_{3} \mathrm{~B}_{1} \mathrm{C}_{2} \mathrm{D}_{2}$, that is, SRB is $40 \%$, nano- $\mathrm{Fe}^{0}$ is $2 \%$, corn cob is 100 mesh, and the corn cob dosage is $3 \%$. The COD release amount of particles is the best under this composition ratio. 


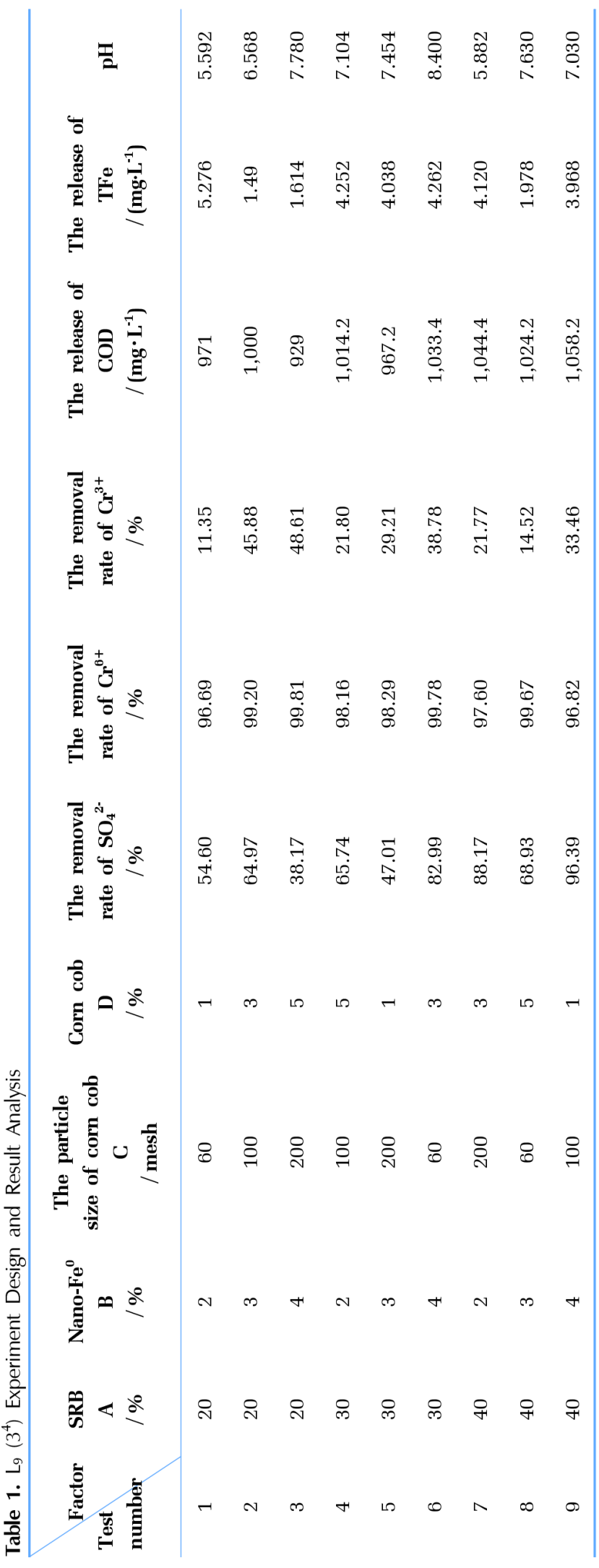

\subsubsection{Analysis the experiment results of $\mathrm{TFe}$}

It can be seen from table S10 that the four factors have insignificant effects on the removal of TFe. According to the range of table S9, the order of influence on TFe release is: $\mathrm{B}>\mathrm{D}>\mathrm{A}>\mathrm{C}$. Therefore, the optimal combination of factors to determine the TFe release amount according to the mean size is $\mathrm{A}_{2} \mathrm{~B}_{1} \mathrm{C}_{1} \mathrm{D}_{1}$, that is, the SRB is $30 \%$, the nano- $\mathrm{Fe}^{0}$ is $2 \%$, the corn cob is 60 mesh, the corn cob dosage is $1 \%$, and the TFe release amount of particles is the best under this composition ratio.

\subsubsection{Analysis the experiment results of $\mathrm{pH}$}

It can be seen from table $\mathrm{S} 12$ that nano-Fe ${ }^{0}$ has a significant influence on the $\mathrm{pH}$ regulation ability of particles among the four factors. According to the range of table S11, the order of influence on $\mathrm{pH}$ is $\mathrm{B}>\mathrm{A}>\mathrm{D}>\mathrm{C}$. Therefore, according to the mean value, the optimal $\mathrm{pH}$ combination is $\mathrm{A}_{2} \mathrm{~B}_{3} \mathrm{C}_{1} \mathrm{D}_{3}$, that is, the $\mathrm{SRB}$ is $30 \%$, the nano- $\mathrm{Fe}^{0}$ is $4 \%$, the corn cob is 60 mesh, and the corn cob dosage is $5 \%$. The $\mathrm{pH}$ raising effect of the particles is the best under this composition ratio.

\subsubsection{Determine the result of orthogonal experiment}

Based on the orthogonal experimental results from 3.1 to 3.6 $\left(\mathrm{A}_{3} \mathrm{~B}_{3} \mathrm{C}_{2} \mathrm{D}_{2}, \mathrm{~A}_{2} \mathrm{~B}_{2} \mathrm{C}_{1} \mathrm{D}_{3}, \mathrm{~A}_{1} \mathrm{~B}_{3} \mathrm{C}_{2} \mathrm{D}_{2}, \mathrm{~A}_{3} \mathrm{~B}_{1} \mathrm{C}_{1} \mathrm{D}_{1}, \mathrm{~A}_{2} \mathrm{~B}_{3} \mathrm{C}_{1} \mathrm{D}_{3}\right)$, the optimal composition ratio of nano-Fe ${ }^{0}$ immobilized particles is $\mathrm{A}_{2} \mathrm{~B}_{3} \mathrm{C}_{1} \mathrm{D}_{2}$, that is, $30 \%$ of SRB, $4 \%$ of nano- $\mathrm{Fe}^{0}, 60$ mesh corn cob particle size, $3 \%$ of corn cob dosage, and the best performance of nano- $\mathrm{Fe}^{0}$ immobilized particles under this composition ratio was determined.

\subsection{Instrument Characterization of Particles}

\subsubsection{EDS analysis}

Nano- $\mathrm{Fe}^{0}$ SRB immobilized particles were prepared according to the optimal ratio determined by the above orthogonal test. The particles before and after the reaction were dried and EDS energy spectrum analysis was carried out. The experimental results were shown in Fig. 5(a) and (b).

It can be seen from Fig. 5(a) that, before the reaction, the $\mathrm{Fe}^{0}$ SRB immobilized nanoparticles mainly contained $\mathrm{C}, \mathrm{O}, \mathrm{Cl}, \mathrm{Ca}$ and Fe elements, and their weight percentages were 10.09\%, $21.90 \%$, $1.09 \%, 1.58 \%$ and $65.34 \%$, respectively. After the reaction, the immobilized particles mainly contained C, O, S, Ca, Cr and Fe elements, and their weight percentages were respectively $9.22 \%$, $20.19 \%, 5.10 \%, 0.44 \%, 4.29 \%$ and $60.57 \%$. After the reaction, S and $\mathrm{Cr}$ elements obviously appeared in the particles. For element $S$ peak, this is because the SRB in the particle dissimilar reduces $\mathrm{SO}_{4}{ }^{2-}$ to form $\mathrm{S}^{2-}$ during the reaction process, and then forms metal sulfide with heavy metal ions or adsorbs the biomass material of corn cob to deposit it on the surface and inside of the particle. Therefore, obvious element S peak appears after the reaction. For the $\mathrm{Cr}$ element peak, the reason is that the particles are immersed in the waste water containing chromium in the reaction process. Under the strong reduction effect of nano- $\mathrm{Fe}^{0}$, the $\mathrm{Cr}^{6+}$ in the water is rapidly transformed into $\mathrm{Cr}^{3+}$. Part of $\mathrm{Cr}^{3+}$ is adsorbed on the particle surface by corn cob and other adsorption materials, while the other part forms metal sulfide precipitation and deposition on the particle surface and internal pores with $\mathrm{S}^{2-}$, resulting in obvious $\mathrm{Cr}$ element peak after the reaction. In addition, compared with before and after the reaction, Fe peak content decreased from $65.34 \%$ 

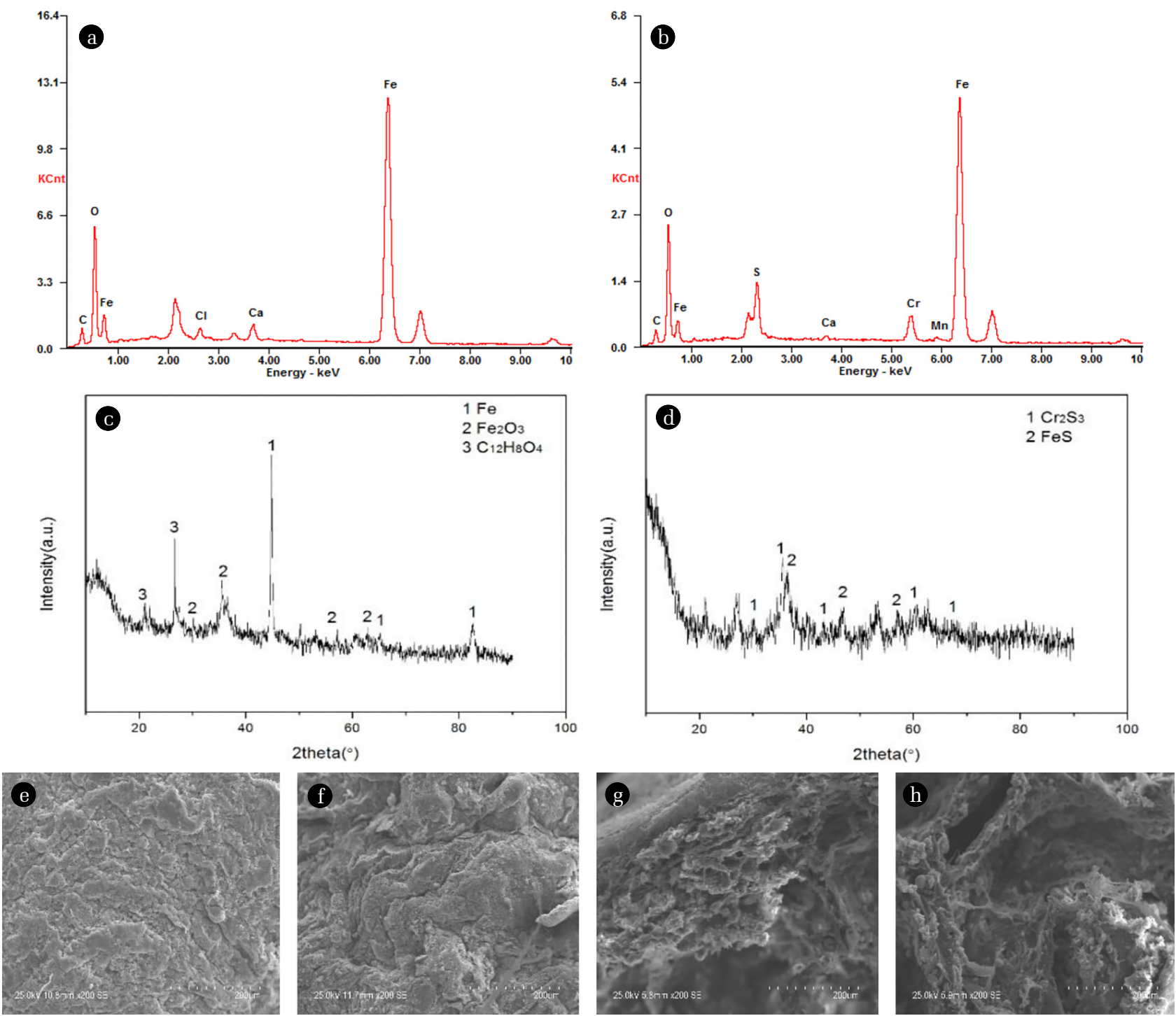

Fig. 5. EDS, XRD and SEM analysis of AMD before and after particles treatment. (a) EDS analysis before reaction of particles. (b) EDS analysis after reaction of particles. (c) XRD analysis before reaction of particles. (d) XRD analysis after reaction of particles. (e) SEM in surface before reaction of particles. (f) SEM in surface after reaction of particles. (g) SEM in cross-section before reaction of particles. (h) SEM in cross-section after reaction of particles.

to $60.57 \%$. This is because part of the elemental nano- $\mathrm{Fe}^{0}$ in the particle reacts with $\mathrm{H}^{+}$in the wastewater to form $\mathrm{Fe}^{2+}$, and then dissociates into the wastewater, so the Fe element peak in the particle decreases. The peaks of other elements did not change much before and after the reaction, indicating that the particles were stable and did not cause a large amount of matrix leakage.

\subsubsection{XRD analysis}

Nano-Fe ${ }^{0}$ SRB immobilized particles were prepared according to the optimal ratio determined by the above orthogonal test. The particles before and after the reaction were dried and ground into 200 mesh powder for XRD analysis. The test results are shown in Fig. 5(c) and (d).

It can be seen from Fig. 5(c) that Fe elements in the nano-Fe ${ }^{0}$
SRB immobilized particles before the reaction mainly exist in elemental iron and $\mathrm{Fe}_{2} \mathrm{O}_{3}$. The existence of $\mathrm{Fe}_{2} \mathrm{O}_{3}$ is mainly due to the fact that the nano- $\mathrm{Fe}^{0}$ in the surface layer of particles is easily oxidized by air. Since it is difficult to completely isolate the air in the experiment, there will be a small amount of $\mathrm{Fe}_{2} \mathrm{O}_{3}$ in the surface layer of particles. Through observation, we found that there were no other elements in the particles except organic compounds. This indicates that the particle purity of the finished product is higher.

After the reaction, two new elements $\mathrm{S}$ and $\mathrm{Cr}$ appear in the particles, and the phase characterized by them by XRD is $\mathrm{Cr}_{2} \mathrm{~S}_{3}$. This further confirms that the removal of $\mathrm{Cr}^{3+}$ by particles is dependent on the metal sulfide precipitation formed by $\mathrm{S}^{2-}$ which is free from the water. In addition, the main existence form of Fe element 
is FeS. This indicates that the $\mathrm{S}^{2-}$ generated by SRB foreignizing reduction of $\mathrm{SO}_{4}{ }^{2-}$ can form precipitation with heavy metal ions on the one hand, and form $\mathrm{FeS}$ with $\mathrm{Fe}^{2+}$, on the other hand, with a more thorough removal effect. Therefore, in the later stage of this experiment, some sulfide precipitation such as FeS can be considered to recover and purify the elemental sulfur, so as to further improve the available potential of elements.

\subsubsection{SEM analysis}

After drying the particles before and after the above reaction, SEM was used to scan the surface and section structure of the particles with a magnification of 200 times. The microscopic changes of the particle structure before and after the reaction were observed, and the reaction process of the particles was analyzed to further reveal the mechanism of the coordinated treatment of AMD by particles. SEM microscanning is shown in Fig.5(e) and (f).

It can be seen from Fig. 5(e) that the particle surface and section surface structure changed greatly before and after the reaction. Before the reaction, the surface texture of particles was uniform and neat, the pores were unobstructed and the size was appropriate. The porosity inside the particle is developed and the permeability is good. This indicates that the prepared finished particles can meet the requirements of adsorption and removal of pollutant ions, and at the same time can better meet the contact of nano- $\mathrm{Fe}^{0}$ material with $\mathrm{H}^{+}$in $\mathrm{AMD}$, and improve the $\mathrm{pH}$ value of $\mathrm{AMD}$.

After the reaction, there was almost no particle deposition on the particle surface, and obvious folds and bulges and large pores and cracks appeared. This is because the finished product particles have large pore structure and strong SRB biological activity, and the heavy metal ions in the waste water can enter into the particles smoothly and react to deposit, so there is no obvious particle deposition on the surface of the particles. As can be seen from the particle cross section, after the reaction, the particle channel becomes narrower, a large number of particles are deposited on the inner wall of the channel, and filaments appear in the channel. This is because the $\mathrm{FeS}$ and $\mathrm{Cr}_{2} \mathrm{~S}_{3}$ generated by the particle reaction enter into the particle through abundant channels and eventually deposit on the inner wall of the channels, causing the obstruction of the channels.

\section{Conclusions}

(1) By conducting a single factor test to determine that the optimal dosage of SRB and nano- $\mathrm{Fe}^{0}$ were $30 \%$ and $3 \%$. The optimal size of corn cob was 60 mesh and the optimal dosage of corn cob was $3 \%$.

(2) Through the orthogonal experiment to determine that when the mass percentage of SRB was $30 \%$, the dosage of nano- $\mathrm{Fe}^{0}$ was $4 \%$ and the dosage of 60 mesh corn cob was $3 \%$, the removal rates of $\mathrm{SO}_{4}{ }^{2-}, \mathrm{Cr}^{6+}$ and $\mathrm{Cr}^{3+}$ were $82.99 \%, 99.78 \%$ and $38.78 \%$, respectively. The release of TFe, COD were 4.26 $\mathrm{mg} \cdot \mathrm{L}^{-1}$ and $1,033.4 \mathrm{mg} \cdot \mathrm{L}^{-1}$, respectively. The $\mathrm{pH}$ value was 8.04 . Under these conditions, it can achieve the best treatment.

(3) The analysis by EDS confirmed that the particles mainly contain $\mathrm{C}, \mathrm{O}, \mathrm{Cl}, \mathrm{Ca}, \mathrm{Fe}$ elements. After the reaction, there were two new elements of $\mathrm{S}$ and $\mathrm{Cr}$ appeared in the particles, and the peak value of Fe decreased. The analysis by XRD showed that the elements $\mathrm{S}$ and $\mathrm{Cr}$ of the particles mainly existed in the form of $\mathrm{FeS}$ and $\mathrm{Cr}_{2} \mathrm{~S}_{3}$ after the reaction. The analysis by SEM showed that the surface and internal structure varied greatly before and after the particle reaction. In summary, particles in the process of dealing with AMD occurred a series of complex reactions.

\section{Acknowledgements}

This research was supported by the National Natural Science Foundation of China (41672247, 41102157, 51304114), Liaoning Province's "Program for Promoting Liaoning Talents" (XLYC1 807159).

\section{Author Contributions}

J. D. (Professor) made the experiment plan and guided the experiment in the whole process. X. W. (Ph.D. student) was in charge of data analysis and paper writing. B. L. (Professor) and Y. Y. (Professor) was in charge of experiment guidance and paper revision. Y. D. (Ph.D. student) and M. W. (Master student) was responsible for water quality analysis and detection.

\section{Reference}

1. Skousen J, Zipper CE, Rose A, et al. Review of passive systems for acid mine drainage treatment. Mine Water Environ. 2017;36(1):133-153.

2. Iakovleva E, Mäkilä E, Salonen J. Acid mine drainage (AMD) treatment: Neutralization and toxic elements removal with unmodified and modified limestone. Ecol. Eng. 2015;81(4):30-40.

3. Riato L, Leira M, Della VB. Development of a diatom-based multimetric index for acid mine drainage impacted depressional wetlands. Sci. Total Environ. 2018;612:214-222.

4. Pozo-Antonio JS, Puente-Luna I, López SL. Microbial treatment of acid mine drainage (AMD): A review. Technol. Cienc. Agua 2017;8(3):75-91.

5. Polat M, Guler E, Akar G. Neutralization of acid mine drainage by Turkish lignitic fly ashes; role of organic additives in the fixation of toxic elements. J. Chem. Technol. Biot. 2010;77(3): 372-376.

6. Sultana M, Mourti C, Tatoulis T. Effect of hydraulic retention time, temperature, and organic load on a horizontal subsurface flow constructed wetland treating cheese whey wastewater. J. Chem. Technol. Biot. 2016;91(3):726-732.

7. Aksu Z, Dönmez G. Combined effects of sucrose and copper(II) ions on the growth and copper(II) bioaccumulation properties of Candida sp. J. Chem. Technol. Biot. 2015;75(9):847-853.

8. Li X, Lan S, Zhang C, et al. The bioenergetics mechanisms and applications of sulfate-reducing bacteria in remediation of pollutants in drainage: A review. Ecotox. Environ. Safe 2018;158:162-170.

9. Kumar N, Chaurand P, Rose J, Diels L, Bastiaens L. Synergistic effects of sulfate reducing bacteria and zero valent iron on zinc removal and stability in aquifer sediment. Chem. Eng. 
J. 2015;260:83-89.

10. Xi Y, Lan S, Li X, et al. Bioremediation of antimony from wastewater by sulfate-reducing bacteria: Effect of the coexisting ferrous ion. Int. Biodeter. Biodegr. 2020;148:104912.

11. Najib T, Solgi M, Farazmand A. Optimization of sulfate removal by sulfate reducing bacteria using response surface methodology and heavy metal removal in a sulfidogenic UASB reactor. $J$. Environ. Chem. Eng. 2017;5(4):3256-3265.

12. Gaikwad R. Review on removal of heavy metals from acid mine drainage. Appl. Ecol. Env. Res. 2008;6(3):81-98.

13. Ting L, Yucui H, Weize W. Formic acid and acetic acid production from corn cob by catalytic oxidation using $\mathrm{O}_{2}$. Fuel Process Technol. 2018;171:133-139.

14. Kumar N, Omoregie E, Rose J, et al. Inhibition of sulfate reducing bacteria in aquifer sediment by iron nanoparticles. Water Res. 2014;51:64-72.

15. Yang L, Jingxin Z, Yaobin Z. Scaling-up of a zero valent iron packed anaerobic reactor for textile dye wastewater treatment: a potential technology for on-site upgrading and rebuilding of traditional anaerobic wastewater treatment plant. Water Sci. Technol. 2017;76(3-4):823-831.

16. Li X, Wu Y, Zhang C, et al. Immobilizing of heavy metals in sediments contaminated by nonferrous metals smelting plant sewage with sulfate reducing bacteria and micro zero valent iron. Chem. Eng. J. 2016;306:393-400.

17. Asli EY, Yayayürük O. Adsorptive performance of nanosized zero-valent iron for $\mathrm{V}(\mathrm{V})$ removal from aqueous solutions. J. Chem. Technol. Biot. 2017;92(8):1891-1898.

18. Qiu X, Fang Z, Liang B, Gu F, Xu Z. Degradation of decabromodiphenyl ether by nano zero-valent iron immobilized in mesoporous silica microspheres. J. Hazard. Mater. 2011;193:70-81.

19. Junzhen D, Yadong R, Junjie G. Best conditions of modification about corncob as SRB fixed carbon source. Chinese J. Environ. Eng. 2017;11(8):118-122.

20. State Environmental Protection Administration. Water and wastewater monitoring and analysis methods. 4th edition. Beijing: China Environ. Sci. Press 2002:102-372.

21. Gil-Garcia C, Lag DG, Fuess LT. Performance improvement of a thermophilic sulfate-reducing bioreactor under acidogenic conditions: Effects of diversified operating strategies. J. Environ. Manage. 2017;207:303-312.

22. Dev S, Roy S, Bhattacharya J. Understanding the performance of sulfate reducing bacteria based packed bed reactor by growth kinetics study and microbial profiling. J. Environ. Manage. 2016;177:101-110.

23. Ma X, Fei B, Jin N, et al. Characteristics of Reduce Cr(VI) by Desulfovibrio SRB7. Microbiol. China 2009;36(9):1324-1328.

24. He Q, Chen H, Wang D, Li H, Ding X, Deng L. Treating $\mathrm{Cr}(\mathrm{VI})$-containing wastewater by a consortium of sulfate reducing bacteria and copper-iron bimetallic particles. Environ. Sci. 2011;32(7):2000-2005.

25. Fuller S, Burke I, Mcmillan D. Population Changes in a Community of Alkaliphilic Iron-Reducing Bacteria Due to Changes in the Electron Acceptor: Implications for Bioremediation at Alkaline Cr(VI)-Contaminated Sites. Water Air Soil Poll. 2015;226(6):1-15.

26. Yong $\mathrm{H}$, Zhaoqian J, Yuta S. Effect of influent $\mathrm{COD} / \mathrm{SO}_{4}{ }^{2-}$ ratios on UASB treatment of a synthetic sulfate-containing wastewater. Chemosphere 2015;130:24-33.

27. Leyva-Ramos R, Bernal-Jacome L, Acosta-Rodriguez I. Adsorption of cadmium(II) from aqueous solution on natural and oxidized corncob. Sep. Purif. Technol. 2005;45(1):41-49.

28. Yi H, Gong S, Wu W, Li Z, Yang L, Xiao H. Progress of Corncob Adsorbent Materials of Heavy Metal Ions. Guangdong Chem. Ind. 2013;40(18):73-74.

29. Gallagher K, Kading T, Braissant O. Inside the alkalinity engine: the role of electron donors in the organomineralization potential of sulfate-reducing bacteria. Geobiology 2012;10(6):518-530.

30. Semerã D, Cajthaml T. Ecotoxicity and environmental safety related to nano-scale zerovalent iron remediation applications. Appl. Microbiol. Biot. 2016;100(23):9809-9819.

31. Liu Z, Li L, Li Z, Tian X. Removal of sulfate and heavy metals by sulfate reducing bacteria in an expanded granular sludge bed reactor. Environ. Technol. 2017;1-31.

32. Dong Y, Di J, Wang X, et al. Dynamic experimental study on treatment of acid mine drainage by bacteria supported in natural minerals. Energies 2020;13:439.

33. Nethaji S, Sivasamy A, Mandal A. Preparation and characterization of corn cob activated carbon coated with nano-sized magnetite particles for the removal of $\mathrm{Cr}(\mathrm{VI})$. Bioresour. Technol. 2013;134(2):94-100.

34. Homhoul P, Pengpanich S, Hunsom M. Treatment of Distillery Wastewater by the Nano-Scale Zero-Valent Iron and the Supported Nano-Scale Zero-Valent Iron. Water Environ. Res. 2011;83(1):65-74.

35. Kijjanapanich P, Pakdeerattanamint K, Lens P, Annachhatre A. Organic substrates as electron donors in permeable reactive barriers for removal of heavy metals from acid mine drainage. Environ. Technol. 2012;33(23):2635-2644.

36. Di J, Wang M, Zhu Z. Experiment on the treatment of acid mine drainage with optimized biomedical stone particles by response surface methodology. Environ. Sci. Pollut. R 2018;25(1): 7978-7990.

37. Zhou L, Zhuang W, Wang X. Potential effects of loading nano zero valent iron discharged on membrane fouling in an anoxic/oxic membrane bioreactor. Water Res. 2017;111:140-146.

38. Stefaniuk M, Oleszczuk P, Yong S. Review on nano zerovalent iron (nZVI): From synthesis to environmental applications. Chem. Eng. J. 2016;287:618-632.

39. Das B, Roy S, Dev S, Das D, Bhattacharya J. Improvement of the degradation of sulfate rich wastewater using sweetmeat waste (SMW) as nutrient supplement. J. Hazard. Mater. 2015; 300:796-807.

40. Piña-Salazar E, Cervantes F, Meraz M, Celis L. Biofilm development during the start-up of a sulfate-reducing down-flow fluidized bed reactor at different $\mathrm{COD} / \mathrm{SO}_{4}{ }^{2-}$ ratios and HRT. Water Sci. Technol. 2011;64(4):910-916.

41. Ren N, Chua H, Chan S, Tsang Y, Sin Ngai. Effects of COD/SO ${ }_{4}^{2-}$ Ratios on an Acidogenic Sulfate-Reducing Reactor. Ind. Eng. Chem. Res. 2007;46(6):1661-1666.

42. Mei Y, Hui L, Di W. Effects of carbon-to-sulfur (C/S) ratio and nitrate $(\mathrm{N})$ dosage on Denitrifying Sulfur cycle-associated Enhanced Biological Phosphorus Removal (DS-EBPR). Sci. Rep-UK 2016;6:1-10. 